\title{
Determination of Elastic Modulus of Spider's Silks
}

\author{
Shigeyoshi OSAKI ${ }^{\dagger}$ and Rie ISHIKAWA* \\ Deparlment of Chemistry, Faculty of Medicine, Nara Medical University, Kashihara, \\ Nara 634-8521, Japan \\ ${ }^{*}$ Faculty of Education, Shimane University, Matsue, Shimane 690-8504, Japan
}

(Received August 30, 2001; Accepted November 9, 2001)

\begin{abstract}
Elastic moduli were determined from the stress-strain curves of draglines secreted from Nephila clavata spiders (Japanese golden-web spiders) collected at different stages of growth. In order to accurately determine the elastic modulus it was necessary to measure the cross sectional area of the same dragline consisting of double filaments used for measuring the stress-strain curves. The elastic modulus was determined to be $c a$. $10 \mathrm{GPa}$ for spiders weighing less than $50 \mathrm{mg}, c a$. $13 \mathrm{GPa}$ for spiders weighing between 50 and $800 \mathrm{mg}$, and $c a .10 \mathrm{GPa}$ for old spiders weighing more than $800 \mathrm{mg}$. The relatively small values of $c a$. $10 \mathrm{GPa}$ for the elastic modulus may come from the relatively large cross sectional area of the draglines for spiders weighing less than $50 \mathrm{mg}$ and from the small value of the elastic limit strength for spiders weighing more than $800 \mathrm{mg}$. It was found that the elastic modulus of spider's draglines consisting of almost amorphous protein molecules was relatively large in comparison with the elastic modulus of several GPa obtained for amorphous synthetic polymers.
\end{abstract}

KEY WORDS Elastic Modulus / Spider / Dragline / Stress-Strain Curve / Age Dependence /

Spider silks, mainly draglines, have been studied from the viewpoint of their mechanical, physicochemical, thermal, optical, ageing, and molecular orientational properties. $^{1-9}$

Since draglines act as a mechanical lifeline supporting a spider's weight, it is intriguing to examine whether the dragline is mechanically strong. The elastic modulus of draglines gives an intrinsic value reflecting the mechanical strength in the region which the stress-strain behavior is linear. The elastic modulus has been estimated by the stress-strain curve and the X-Ray diffraction methods. ${ }^{9-11}$ When the elastic modulus was determined from the stress-strain curve, it was assumed in ref 10 that there was a distribution of fiber diameters among the different fibers and that the stress-strain behavior of each fiber would be identical. ${ }^{10}$ When the bundles consisting of more than 5000 filaments (see ref 11) were used for the determination of X-Ray modulus, ${ }^{11}$ it might be difficult to count the number of filaments, to determine the total area by accurately measuring the cross sectional area of each filament and to evaluate the stress applied only to the crystalline region of dragline consisting of almost amorphous protein. ${ }^{12}$

In previous papers, ${ }^{13,14}$ one of authors reported that the elastic limit strength of the dragline was about twice the spider's weight and that the dragline gave the most coefficient safety as a mechanical lifeline. At that time, he measured stress-strain curves of more than one thousand samples. Since then, he has come to question whether the elastic modulus had been accurately deter- mined because of the following four problems. ${ }^{15}$ First, there is a difficulty in preparing samples for the mechanical measurements of draglines. If a force greater than the elastic limit strength is applied to a dragline, the dragline cannot be used as a sample because of the mechanical hysteresis. Secondly, the accuracy of the data in mechanical measurements has been very poor because of difficulties in measuring the markedly low stress and strain. Thirdly, it is very difficult to obtain only the true dragline as a sample from a spider's body because the spider secretes seven kinds of threads. ${ }^{12}$ Fourthly, it has been difficult to measure the cross sectional area by using the same dragline used for the mechanical measurements. These problems have caused difficulties in estimating the elastic modulus accurately.

The present study focuses on resolving several problems for the mechanical measurement of spider's draglines and then on accurately determining the elastic modulus of dragline.

\section{EXPERIMENTAL}

\section{Sample Preparation}

The samples used here were draglines, which act as a lifeline for spiders to support their weight, ${ }^{13,14}$ secreted from Nephila clavata spiders (Japanese goldenweb spiders) falling from a wooden bar in the laboratory (see Figure 1) in order to avoid the mechanical hysteresis of the draglines ascribed to the force above the elastic limit strength. The weight $(W)$ of the Nephila

${ }^{\dagger}$ To whom correspondence should be addressed (E-mail: s-osaki@naramed-u.ac.jp). 


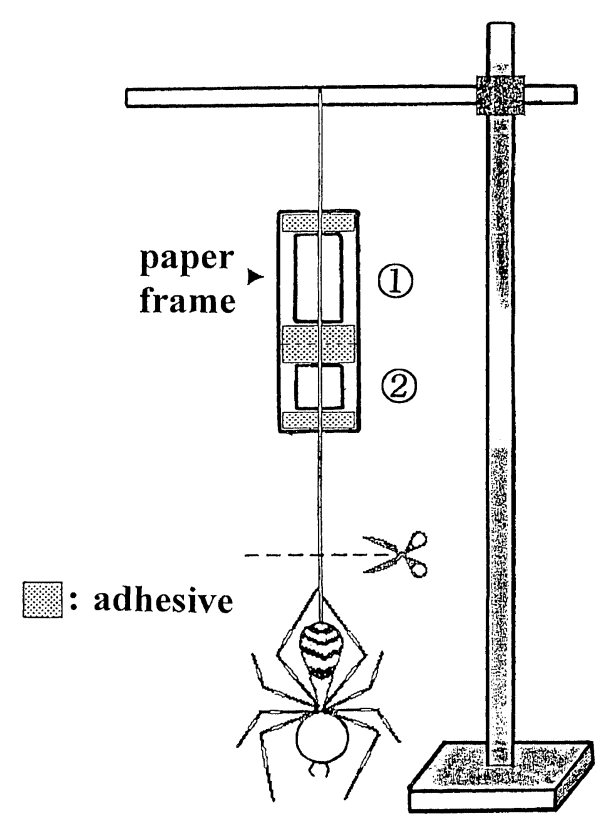

\section{(1):mechanical (2):SEM}

Figure 1. Schematic figure for preparing sample draglines of mechanical measurements and for a scanning electron microscopic observation from an Nephila clavata spider (Japanese golden-web spider) which is falling from a wooden bar.

clavata spider in Japan increases exponentially from juvenile in spring to mature in autumn. ${ }^{14}$ For example, spider's weight increases from about $\mathrm{mg}$ in spring, through about $50 \mathrm{mg}$ in August, up to about $1 \mathrm{~g}$ in late autumn. It become possible to recognize the difference in the sex for spiders weighing more than $50 \mathrm{mg}$ even though it is very difficult to differentiate the sex for spiders weighing less than $50 \mathrm{mg}$. Around $50 \mathrm{mg}$ female spiders continue to increase their weight rapidly while male spiders do not increase their weight. At several stages of spiders' lives we carefully obtained draglines such that force above the elastic limit strength was not be applied to the draglines, in a manner similar to a recently published method. ${ }^{13,14}$ The draglines were stuck to both sides of a paper frame covered with an adhesive so that the force above the elastic limit strength should not be applied to the draglines which were set in the instrument for the mechanical measurements and were prepared as samples for mechanical measurements and scanning electron microscopy (SEM) (see Figure 1). The length of sample draglines for mechanical measurements was $4 \mathrm{~cm}$. We ascertained whether the samples were true draglines consisting of double filaments by using SEM, and then measured the stress-strain curves. The stress-strain curves were carefully measured with high accuracy using a modified instrument manufactured by Instron, Japan with a stretching ve-

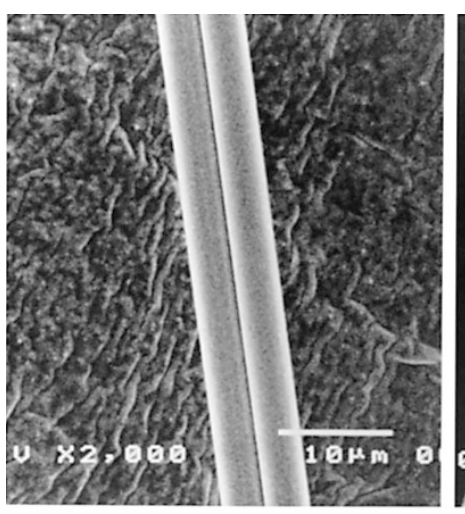

a

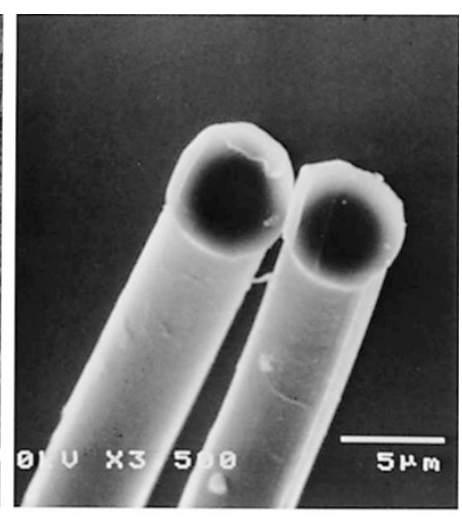

b
Figure 2. Photographs of a dragline from an Nephila clavata spider observed by scanning electron microscope. The dragline consists of double filaments. a, side view. b, cross section view.

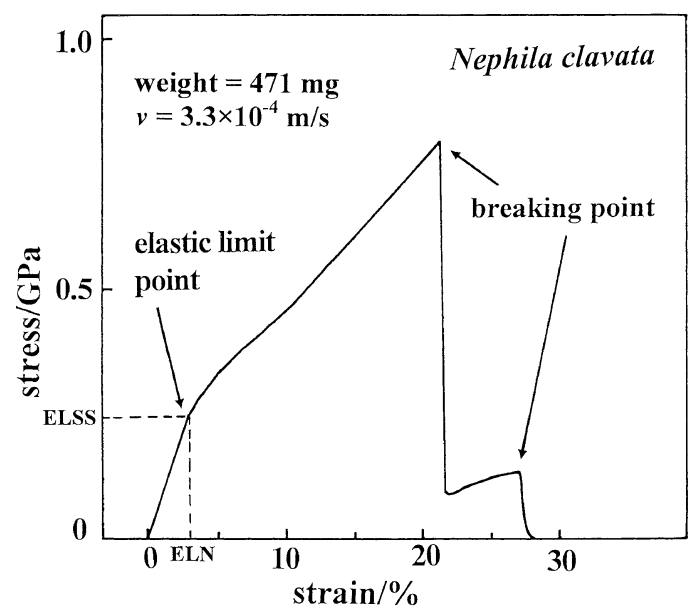

Figure 3. Stress-strain curve obtained for a dragline secreted from an Nephila clavata spider with a weight of $471 \mathrm{mg}$ at a stretching velocity of $3.3 \times 10^{-4} \mathrm{~m} \mathrm{~s}^{-1}$. Elastic limit stress (ELSS) and elastic limit strain (ELN) are defined, respectively, as the stress and the strain at the elastic limit point where the stress-strain behavior changes from linear to nonlinear.

locity of $3.3 \times 10^{-4} \mathrm{~m} \mathrm{~s}^{-1} \cdot{ }^{13,14}$ The mechanical measurements were repeated four times for four samples prepared from the same spider, and then the data were averaged. The fine structure of each dragline was observed using SEM manufactured by JEOL, Japan and the cross sectional area was determined from the diameter of the double filaments constituting the dragline (see Figure 2). ${ }^{14}$

In the stress-strain curve (see Figure 3) we can determine the elastic limit stress (ELSS) and the elastic limit strain (ELN) defined, respectively, as the stress and the strain at the elastic limit point where the stress-strain behavior changes from linear to nonlinear. ${ }^{13,14}$

The errors in the observed values of elastic limit stress, elastic limit strain, cross section area, and elastic modulus were $5 \%, 5 \%, 5 \%$, and $8 \%$, respectively. 


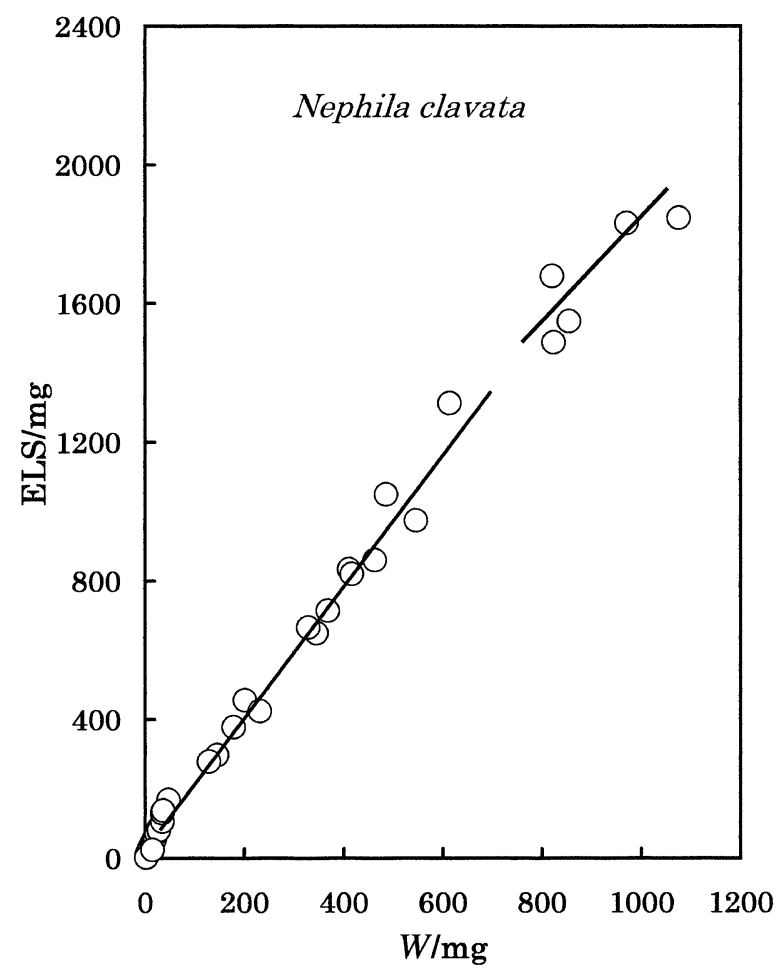

Figure 4. Elastic limit strength ELS of draglines secreted from Nephila clavata spiders plotted against spider weight $W$. The stretching velocity was $3.3 \times 10^{-4} \mathrm{~m} \mathrm{~s}^{-1}$.

\section{Elastic Modulus}

The elastic modulus $(E)$ is defined by ${ }^{16}$

$$
E=(F / S) /(\Delta L / L)
$$

Here, $F$ is the force applied to a dragline, $S$ is the cross sectional area of double filaments, $L$ is the initial length of the dragline, and $\Delta L$ is the elongation of the dragline when the $F$ is applied. The $F$ and $\Delta L$ are determined from the force-elongation curve within the elastic limit point and the $S$ from the electron scanning microscopy.

Although we observe a dragline as a single line with the naked eye, the electron microphotograph shows that the dragline consists of double filaments. ${ }^{14}$ Each of the filaments has a nearly circular cross section with a minimum surface.

\section{RESULTS}

Figure 4 shows the relationship between the elastic limit strength ELS of a dragline and the spider weight $(W)$. The elastic limit strength increases with increasing the spider weight. Here, the elastic limit strength ELS is given by the elastic limit stress ELSS times the cross sectional area $\mathrm{S}$. Changes in the slope of the elastic limit strength $v s$. spider weight were observed at $c a .50 \mathrm{mg}$ and $c a .800 \mathrm{mg}$. The slope was determined to be $c a .3 .0$ for spider babies less than $50 \mathrm{mg}$, and $c a .2 .0$ for spiders

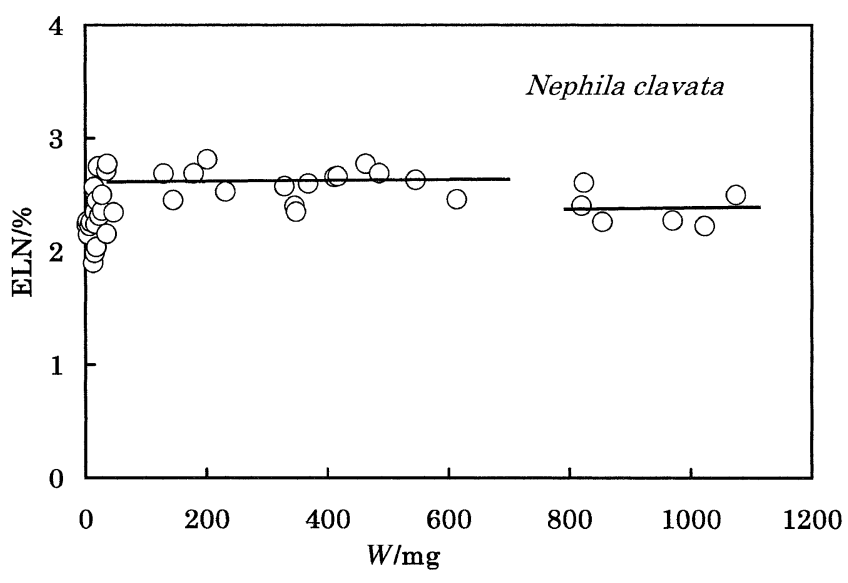

Figure 5. Elastic limit strain ELN of draglines secreted from Nephila clavata spiders plotted against spider weight $W$. The stretching velocity was $3.3 \times 10^{-4} \mathrm{~m} \mathrm{~s}^{-1}$.

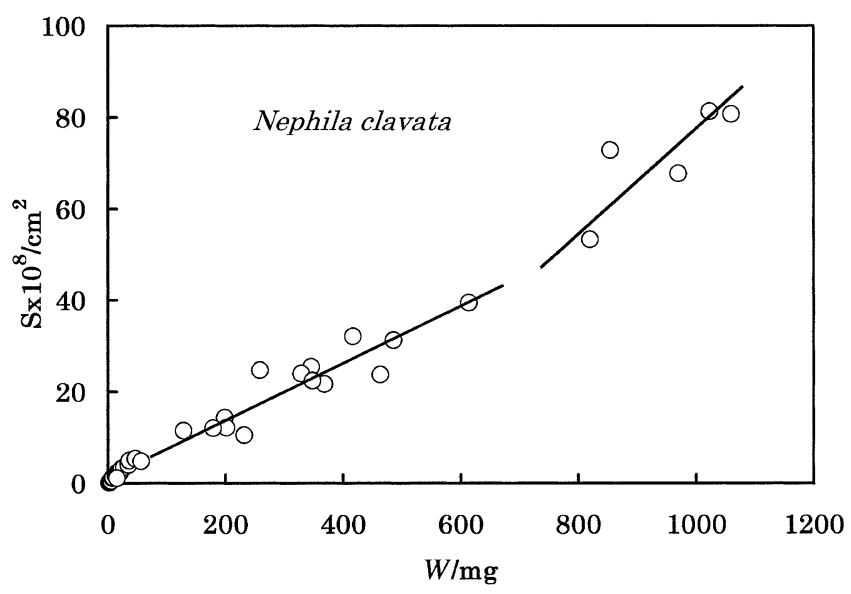

Figure 6. Relationship between the cross sectional area $S$ of draglines and the spider weight $W$ for Nephila clavata spiders.

weighing between $50 \mathrm{mg}$ and $800 \mathrm{mg}$, and $c a .1 .8$ for old spiders weighing more than $800 \mathrm{mg}$.

Figure 5 shows the relationship between the elastic limit strain ELN of a dragline and the spider weight $W$. The elastic limit strain was determined to be $2.31 \pm$ $0.25 \%$ for spiders weighing less than $50 \mathrm{mg}, 2.60 \pm$ $0.14 \%$ for spiders between $50 \mathrm{mg}$ and $800 \mathrm{mg}$, and $2.38 \pm 0.15 \%$ for spiders more than $800 \mathrm{mg}$.

Figure 6 shows the relationship between the cross sectional area $(S)$ of a dragline and the spider weight $W$. The cross sectional area increases with increasing spider weight. We can observe small breaks at $c a$. $50 \mathrm{mg}$ and $c a .800 \mathrm{mg}$. The slope was determined to be $12.6 \times 10^{-6}$ for baby spiders weighing less than $50 \mathrm{mg}$, $6.0 \times 10^{-6}$ for spiders weighing between $50 \mathrm{mg}$ and $800 \mathrm{mg}$, and $9.3 \times 10^{-6}$ for spiders weighing more than $800 \mathrm{mg}$. The gradient was smaller for spiders weighing between $50 \mathrm{mg}$ and $800 \mathrm{mg}$ than for those weighing less than $50 \mathrm{mg}$ or more than $800 \mathrm{mg}$.

By using these data of ELS, ELN, and $S$, the elastic modulus $(E)$ was determined for draglines of spi- 
a)

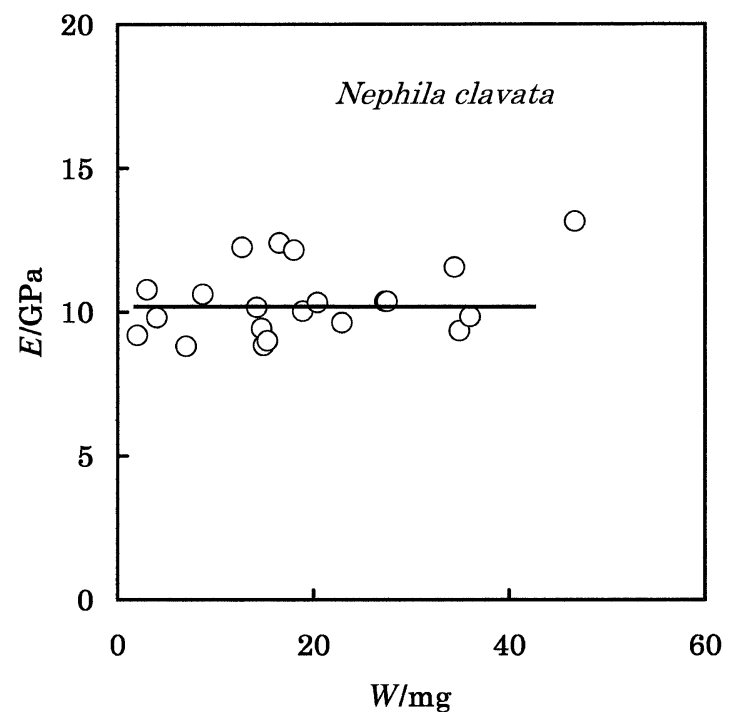

b)

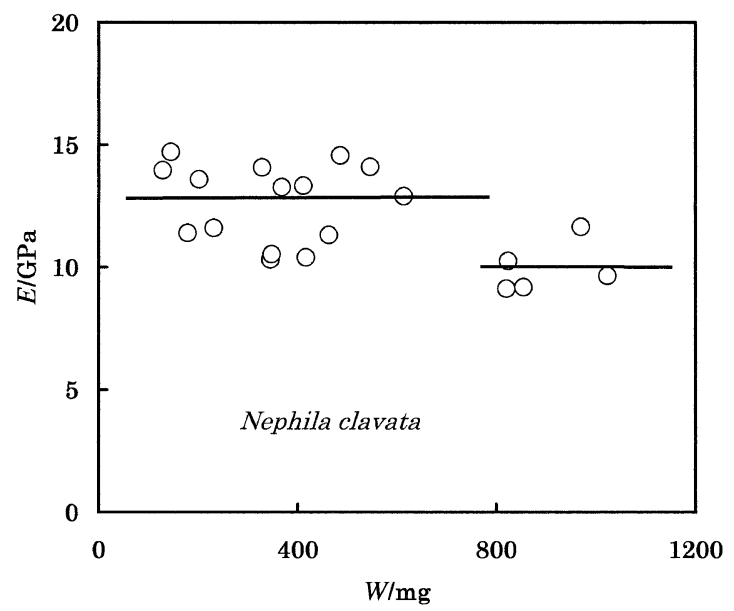

Figure 7. a, Elastic modulus $E$ of draglines secreted from Nephila clavata spiders less than $50 \mathrm{mg}$ is plotted against spider weight $W$. b, Elastic modulus $E$ of draglines secreted from Nephila clavata spiders more than $50 \mathrm{mg}$ is plotted against spider weight $W$. The stretching velocity was $3.3 \times 10^{-4} \mathrm{~m} \mathrm{~s}^{-1}$.

ders with different weights. Figure 7 a shows the elastic modulus for spiders weighing less than $50 \mathrm{mg}$. The elastic modulus was determined to be $10.3 \pm 1.2 \mathrm{GPa}$. Figure $7 \mathrm{~b}$ also shows the elastic modulus for dragline of spiders weighing more than $50 \mathrm{mg}$. The moduli were determined to be $12.9 \pm 1.7 \mathrm{GPa}$ for spiders weighing between $50 \mathrm{mg}$ and $800 \mathrm{mg}$ and $10.0 \pm 1.0 \mathrm{GPa}$ for spiders weighing more than $800 \mathrm{mg}$. The relatively small values of $c a .10 \mathrm{GPa}$ for baby spiders and old spiders may come from the relatively large cross sectional area of the dragline and from the relatively small value of elastic limit strength, respectively. Thus, it was found that the elastic modulus closely depended on the stage of spider growth.

\section{DISCUSSION}

In the present study, we observed two breaks in the relationship of elastic modulus $v s$. spider weight. The first break at about $50 \mathrm{mg}^{17}$ corresponds to the season when the difference in the sex of Nephila clavata spiders is able to be clearly recognized. The second break at about $800 \mathrm{mg}$ gave a small change in elastic limit strength, elastic limit strain and cross sectional area. This may come from a rapid change in spider weight due to the pregnancy. At the present stage, however, the exact reason on the second break is not made clear.

On the other hand, Becker et al. ${ }^{11}$ reported that the X-Ray modulus of draglines out of Nephila clavipes was $c a .17 \mathrm{GPa}$, although some problems were identified with the measurements as described in the Introduction. Such a value was comparable to the elastic moduli determined in the present study.

The most important issue when determining an accurate elastic modulus is to obtain the true dragline from spiders and then to measure the cross sectional area of the same draglines used to measure the stress-strain curve.

It was found that the elastic moduli of draglines, which consist of almost amorphous region, ${ }^{12}$ determined in the present study were much larger than the values of $c a$. $2 \mathrm{GPa}$ obtained for amorphous polystyrene polymer. ${ }^{18}$ Such a difference may be ascribed to the differences in fine structure between the draglines and the synthetic amorphous polymers. Especially, the high modulus of the draglines may be ascribed to the $\beta$-sheet structure of protein molecules and also to the fine structure consisting of uniaxially oriented protein molecules by measurements of X-Ray diffraction and infrared dichroism. ${ }^{12}$

Finally, the elastic modulus should be determined for draglines having no mechanical hysteresis and discussed for draglines at different stages of Nephila clavata spider's growth.

In the near future, we will try to measure the elastic moduli of draglines secreted from various kinds of spiders, and to clarify the mechanical functions of draglines and the relationship between the mechanical properties and the fine structures of draglines.

\section{REFERENCES}

1. R. W. Work and N. Morosoff, Text. Res. J., 46, 349 (1982).

2. S. Osaki, Acta Arachnologica, 37, 69 (1989).

3. S. Osaki, Acta Arachnologica, 38, 21 (1989).

4. S. Osaki, Acta Arachnologica, 43, 1 (1994).

5. S. Osaki, Acta Arachnologica, 46, 1 (1997). 
6. S. Osaki, Nature, 347, 132 (1990).

7. A. H. Simmons, C. A. Michal, and L. W. Jelinski, Science, 271, 84 (1996).

8. Y. Termonia, Macromolecules, 27, 7378 (1994).

9. P. M. Cunniff, S. A. Fossey, M. A. Auerbach, and J. W. Song, "Silk Polymers", American Chemical Society, Washington, D. C., 1995, p 234.

10. J. C. Zemlin, U. S. Army Natick Laboratories, Natick MA, Technical Report TR 69-29-CM (AD 684333), 1968.

11. A. M. Becker, D. V. Mahoney, P. G. Lenhert, R. K. Eby, D. Kaplan, and W. W. Adams, "Silk Polymers", American Chemical Society, Washington, D. C., 1995, p 185.
12. S. Osaki, Journal of Synthetic Organic Chemistry, Japan, 43, 828 (1985).

13. S. Osaki, Nature, 384, 419 (1996).

14. S. Osaki, Int. J. Biol. Macromol., 24, 283 (1999).

15. S. Osaki, presented at 2000 International Chemical Congress of Pacific Basin Societies, Macro-7, No.897, Hawaii, 2000.

16. J. Prescott, “Applied Elasticity”, Dover Pub., Inc., New York, N.Y.,1924, p 13.

17. S. Osaki, "Polymer Preprints, Japan", 1999, vol. 48, no. 4, p 842 .

18. K. Nakamae, T. Nishino, K. Hata, and T. Matsumoto, Kobunshi Ronbunshu, 42, 211 (1985). 